\title{
Time-Dependent Behavior Prediction, Serviceability and Sustainability Problems for High-Performance Concrete Bridges
}

\author{
Banti A. Gedam ${ }^{1(\bowtie)}$, N.M. Bhandari ${ }^{2}$, and Akhil Upadhyay ${ }^{3}$ \\ ${ }^{1}$ Council of Scientific and Industrial Research - Central Building Research \\ Institute, Roorkee, CSIR-CBRI, Roorkee, Uttarakhand, India \\ bantiagedam@cbri.res.in \\ ${ }^{2}$ Indian Institute of Technology Jodhpur, Jodhpur, Rajasthan, India \\ ${ }^{3}$ Indian Institute of Technology Roorkee, Roorkee, Uttarakhand, India
}

\begin{abstract}
The post-tensioned concrete I-girder superstructure bridge made by high-performance concrete (HPC) typically exhibits deceptive time-dependent behavior issues with age of concrete. The most common changes are observed deformation, top and bottom fiber stress variation and loss of pre-stress in I-girder due to the secondary effects of shrinkage and creep in concrete. However, in design optimistic expectation of the time-dependent behavior of several post-tensioned concrete I-girder bridges are premature by the existing bridge code, design specification and available prediction models. Nevertheless, about 1-10 years the time-dependent behavior is observed inaccurate in prediction and introduced serviceability and sustainability problems. Consequently, more study is needed toward the time-dependent behavior prediction of the concrete bridges using HPC shrinkage and creep dataset and existing material prediction models. In the present study author's own an experimentally measured HPC shrinkage and creep database is considered from the literature Gedam et al. 2015 and for same shrinkage and creep are predicted using existing material models such as the American Concrete Institute (ACI), the $f i b$ model code 2010 ( $f i b$ ), the Bazant and Bawaja (B3) and the Gardner and Lockman (GL). The results experimentally measured of the shrinkage and creep and predicted by existing material models are incorporated in incremental time-step analysis method to obtain time-dependent behavior results of the simply supported post-tensioned I-girder up to 800 days. Furthermore, outcome long-term behavior results from both an experimental and models are comparatively studied. It has been observed in comparative studies that the existing shrinkage and creep prediction models are not found sophisticated in prediction of the HPC shrinkage and creep properties. Also, it has a probability that in the conventional analysis, design and regional construction, use of any one out of the four existing material models may be produced serviceability and sustainability issues in long-term behavior prediction. In fact, these material models needed re-evaluation and modification, especially local environmental condition and indigenously sourced concrete materials properties.
\end{abstract}




\section{Nomenclature}

\begin{tabular}{|c|c|}
\hline \multicolumn{2}{|c|}{ The following symbols are used in this paper: } \\
\hline$c_{1}$ & Top fiber neutral axis depth \\
\hline$c_{2}$ & Bottom fiber neutral axis depth \\
\hline$M_{o}$ and $M_{l}$ & Midspan moment due to superimposed dead load and live load \\
\hline$P i$ & Initial prestress \\
\hline$S_{t}$ and $S_{b}$ & $\begin{array}{l}\text { Section moduli with respect to the top }\left(I_{c} / c_{1}\right) \text { and bottom }\left(I_{c} / c_{2}\right) \text { surface of } \\
\text { the girder }\end{array}$ \\
\hline$n-1$ & Beginning of a particular time step \\
\hline$n$ & End of the aforementioned time step \\
\hline$\varphi_{p i}$ & $\begin{array}{l}\text { First term is the instantaneous curvature occurring immediately upon the } \\
\text { application of initial prestress } P i\end{array}$ \\
\hline$d_{\varphi 1}$ & $\begin{array}{l}\text { Second term is a change in curvature corresponding due to loss of } \\
\text { prestress considered PCI Committee report (1975) and Maguru et al. } \\
\text { (1965) from creep, shrinkage, and relaxation coefficient and time funtions }\end{array}$ \\
\hline$d_{\varphi 2}$ & $\begin{array}{l}\text { Third term is a change in curvature resulting from the direct effect of } \\
\text { concrete creep under sustained loading and service conditions }\end{array}$ \\
\hline & Radius of gyration $\left(I_{c} / A_{c}\right)$ \\
\hline
\end{tabular}

\section{Introduction}

The post-tensioned concrete I-girder bridge's serviceability and sustainability are mainly affected due to time-dependent concrete material properties i.e. shrinkage and creep. It has observed that some of the concrete bridges built in last 2-3 decade were shown distress in early service life, excessive deflection and transverse cracking in bridge deck due to lack of the understating of time-dependent concrete materials properties. This problem attracted very serious attention in the concrete bridges not only in India but also in the Asian, European and American subcontinents. According to Mehta (1997) in the United States the National Cooperative Highway Research Program's reported that more than one hundred thousand concrete bridge deck were shown full depth transverse cracking before the concrete was one month matured. Similarly, Bazant et al. (2011a, b) reported that the 56 segmental concrete bridges were shown excessive deflections which could not be predicted properly by the existing shrinkage and creep models i.e. ACI, fib and GL through analysis. However, the B3 model in some cases gives better results, but needs more study and improvement in the area of shrinkage and creep prediction especially for HPC properties. Furthermore, to prove the pervasiveness of the appropriate material model, Bazant et al. (2011a, b) reported that the cause of major distress and serviceability loss of the Koror-Babeldaob (KB) Bridge due to the shrinkage and creep in concrete (see Fig. 1). The KB pre-stressed segmental erected box girder bridge was constructed in the year 1977 and had a world record span of $241 \mathrm{~m}$ long. The final excessive deflections at mid-span were expected, according to the CEB-FIP (1970-1972) as $0.88 \mathrm{~m}$, ACI (1971) as $0.71 \mathrm{~m}$ and McDonald et al. (2003) as $0.737 \mathrm{~m}$. Nevertheless, after 18 years, the deflection at mid-span had been measured $1.61 \mathrm{~m}$ (see Fig. 1b) which shows gross 


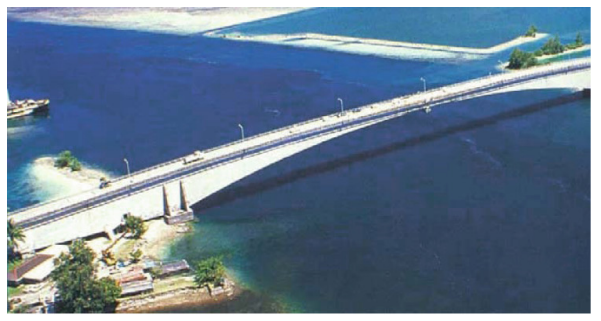

(a)

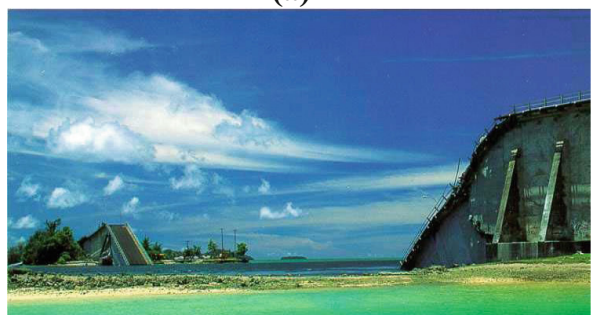

(c)

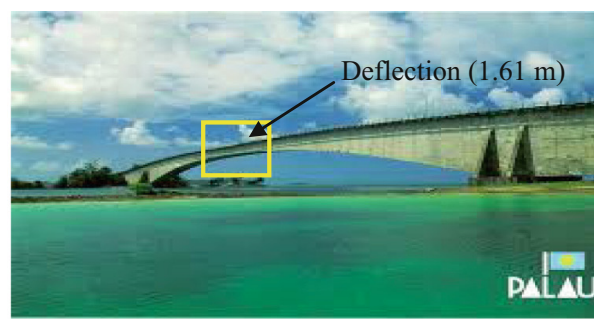

(b)

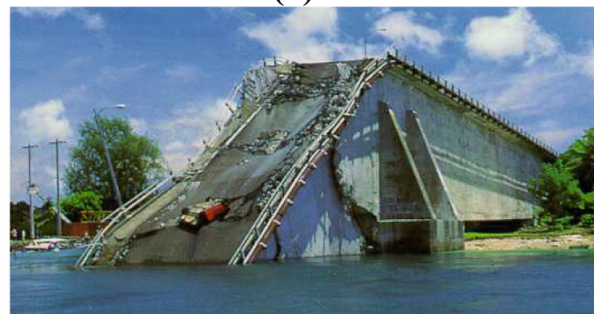

(d)

Fig. 1. (a) Koror-Babeldaob Bridge in Palau (in 1977); (b) 18 year later deflection $1.61 \mathrm{~m}$ (compared to design camber); (c) Koror-Babeldaob Bridge after the collapse (in 1996); (d) Babeldaob side after the collapse (in 1996) (image courtesy from internet resource and Bazant et al. 2012)

underestimation by the material models and in the year 1996 this bridge was collapsed with fatalities and many injuries (see Fig. 1c and d). This incident attracted very much attention of the many researchers and scientists to find reasons for early loss of the serviceable life and sustainability issues of the concrete bridges due to secondary effects of shrinkage and creep in concrete.

\section{Objective and Scope}

In this study, to prove the importance of an appropriate material model in prediction of time-dependent behavior of the post-tensioned I-girder bridge. An analytical study is carried out using an experimental measured HPC shrinkage and creep database, and existing material models, namely ACI, fib, B3, GL. Basically, the time-dependent shrinkage and creep of HPC and relaxation of the pre-stressed steel are responsible for the time-dependent behavior, serviceability and sustainability of post-tensioned I-girder PCI DH (1975). Therefore, an incremental time-step analytical method procedure is adopted on excel platform, which has been used to predict time-dependent behavior of post-tensioned I-girder. The algorithm used for prediction of the time-dependent response has been validated using an experimental results reported in the literature Nilson (1987). In conclusion, the time-dependent behavior of post-tensioned I-girder bridge for M50 grade HPC mix properties is investigated using an experimental and prediction models of shrinkage and creep, and discussion on outcome results for serviceability and sustainability issues of the HPC bridge is presented. 


\section{Experimental Data Consideration}

In the present study, HPC mix of M50 grade (see Table 1) and its relevant mechanical and micromechanical properties have been considered from Gedam et al. (2015) and (2014). The influence of the shrinkage and creep were observed using locally available concrete materials, i.e. cement, fine sand, course aggregate, superplasticizer etc. The experimentally measured results of shrinkage and creep for HPC M50 grade concrete up to 800 days are shown in Fig. 2 along with existing models predicted results as a comparatively and the same results have been considered for critical evaluation of the post-tensioned I-girder bridge to find out time-dependent behavior.

Table 1. HPC mix proportions for shrinkage and creep measurement

\begin{tabular}{l|l|l}
\hline HPC mix composition & Unit & HPC mix proportion \\
\hline Grade of concrete & Grade & M50 \\
\hline Cement & $\mathrm{kg} / \mathrm{m}^{3}$ & 425 \\
\hline Fine aggregate & $\mathrm{kg} / \mathrm{m}^{3}$ & 709 \\
\hline Coarse aggregate & $\mathrm{kg} / \mathrm{m}^{3}$ & 1150 \\
\hline Water & $\mathrm{kg} / \mathrm{m}^{3}$ & 148.75 \\
\hline Superplasticizer G-51 & $\mathrm{kg} / \mathrm{m}^{3}$ & 1.7 \\
\hline w/c & - & 0.35 \\
\hline Slump & $\mathrm{mm}$ & $120 \pm 5$ \\
\hline v/s of cylinder & $\mathrm{mm}$ & 38 \\
\hline$f_{c} k_{28}$ days of cube & $\mathrm{MPa}$ & 61.18 \\
\hline$E_{28}$ days of cylinder & $\mathrm{MPa}$ & 33484 \\
\hline$t_{0}$ and $t_{s}$ & $\mathrm{Days}$ & 28 \\
\hline
\end{tabular}
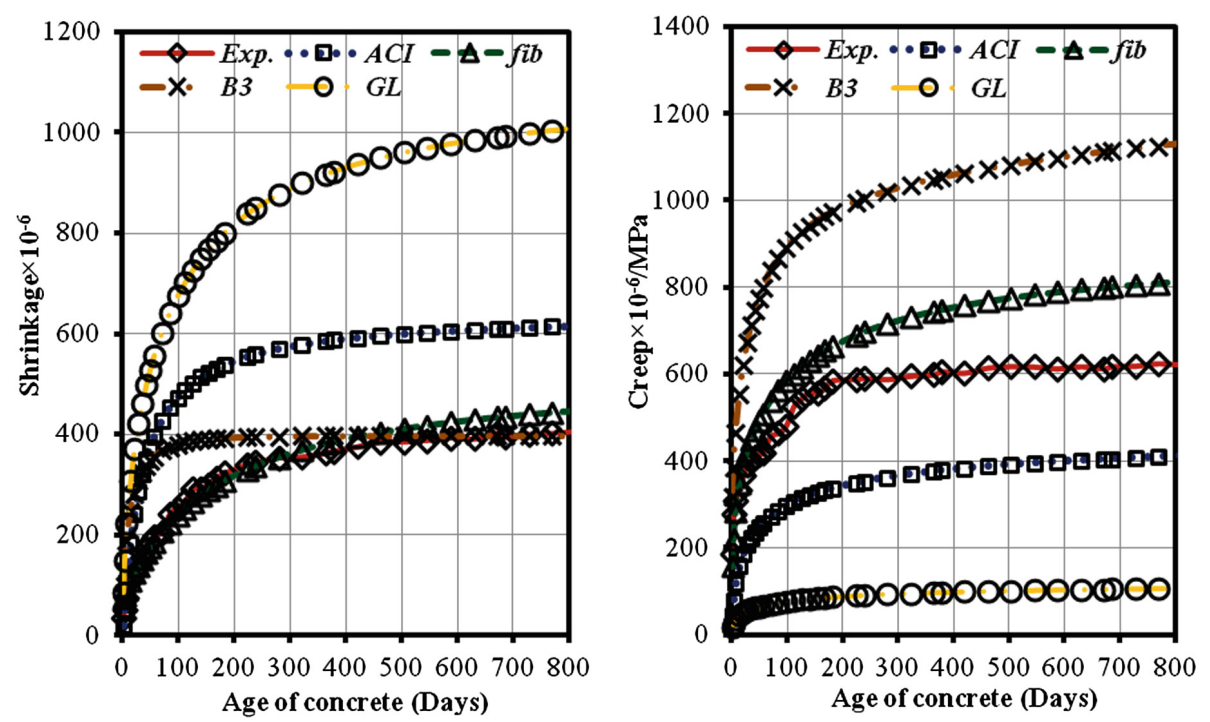

Fig. 2. Time-dependent variation of experimental measured shrinkage and creep along with existing material model's prediction for M50 grade concrete 


\section{Incremental Time-Step Method}

A reasonably accurate estimation of the time-dependent behavior is an important parameter to ensure that the structure built in such concrete performs satisfactorily specially in long-term and service. Hence, the incremental time-step analysis method is adopted on excel platform to evaluate the time-dependent behavior of the HPC girder.

\subsection{Incremental Time-Step Fiber Stress Distribution}

The stresses variation at top and bottom fiber in girder can be calculated with respect to time as follows:

Top fiber stress

$$
f_{t}=\frac{P_{i}}{A_{c}}\left(1-\frac{e_{x} c_{1}}{r^{2}}\right)+\frac{M_{0}}{S_{t}}+\frac{M_{l}}{S_{t}}
$$

Bottom fiber stress

$$
f_{b}=\frac{P_{i}}{A_{c}}\left(1+\frac{e_{x} c_{2}}{r^{2}}\right)-\frac{M_{0}}{S_{b}}-\frac{M_{l}}{S_{b}}
$$

\subsection{Incremental Time-Step Deformations}

The time-dependent deformations variation is calculated on the basis of curvature equations and for computational purpose the time-dependent change in curvature after pre-stress losses have been considered in three parts by using the following equations from Nilson (1987). The general expression to obtain the total curvature $\varphi_{p t}$ after losses at the end of a time intervals at any section can be expressed as follows:

Curvature after losses

$$
\varphi_{p t}=\underbrace{\frac{P_{i} e_{x}}{E_{c i} I_{c}}}_{\varphi_{p i}}+\underbrace{\sum_{0}^{t}\left(P_{n-1}-P_{n}\right) \frac{e_{x}}{E_{c} I_{c}}}_{d \varphi_{1}}-\underbrace{\sum_{0}^{t}\left(C_{n}-C_{n-1}\right) P_{n-1} \frac{e_{x}}{E_{c} I_{c}}}_{d \varphi_{2}}
$$

\subsection{Prestress Tendon}

In incremental time-step method, total prestress losses for I-girder member is computed as per conventional practice. The losses included due to shrinkage and creep of concrete, friction, anchorage slip, elastic shortening and steel relaxation, respectively. All losses are interdependent phenomenon, and therefore, to deal with such complex 
problem the relaxation of steel is evaluated using the following equation which was proposed by Maguru et al. (1964) and still applicable for all existing code and design specification.

Loss of stress in the steel due to relaxation

$$
\frac{f_{p}}{f_{p i}}=1-\frac{\log \left(t_{h}\right)}{10}\left(\frac{f_{p i}}{f_{p y}}-0.55\right)
$$

\subsection{Time-Dependent Material Models}

The four existing material models ACI, fib, B3 and GL predicted results for HPC M50 grade concrete are implemented in incremental time-step analysis method to predict the time-dependent behavior of HPC I-girder Gedam et al. (2014). In practice, the existing material models result in either underestimation/overestimation of the actual timedependent behavior of HPC I-girder. Hence, the experimental measured shrinkage and creep database has also been used in incremental time-step analysis method for a critical appraisal Gedam et al. (2013). Thus, predicted time-dependent behavior of girder is based on the required material models as well as experimental data based.

\subsection{Post-tensioned I-Girder Details}

The simply-supported post-tensioned I-section girder total effective span length $l=12200 \mathrm{~mm}$ is prestressed by a straight tendon at an eccentricity of $e_{x}=131 \mathrm{~mm}$ throughout (cross section details are shown in Fig. 3). The tendon area is $A_{p}=623$ $\mathrm{mm}^{2}$; initial prestressing applied $f_{p i}=1207 \mathrm{MPa}$; the ultimate strength of cable $f_{y}=1448 \mathrm{MPa}$; modulus of elasticity of prestressing cable $E_{p}=186 \times 10^{3} \mathrm{MPa}$; the concrete strength at age of 28 days is $61.18 \mathrm{MPa}$; Concrete parameters considered such as cross-section area of beam section $A_{c}=114 \times 10^{3} \mathrm{~mm}^{2}$; moment of inertia

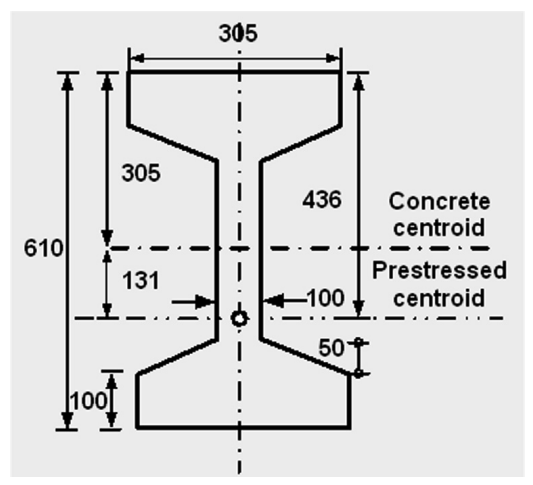

Fig. 3. Cross-sectional details of simply supported I-girder 
$I_{c}=49.9 \mathrm{~mm}^{4}$; modulus of elasticity of concrete $E_{c}=33.484 \times 10^{3} \mathrm{MPa}$; radius of gyration $r^{2}=44 \times 10^{3} \mathrm{~mm}^{2}$; self weight of concrete beam $w_{0}=2.7 \mathrm{kN} / \mathrm{m}$; The service live load $w_{l}=6.3 \mathrm{kN} / \mathrm{m}$ considered at 28 day maturity of concrete. The load case (LC) for critical appraisal considered as only self weight + time-dependent prestress force loss + live load.

\section{Results and Discussion}

The analytical procedure of incremental time-step method for simply supported post-tensioned I-girder on excel platform is used to compute time-dependent deformation response, fiber stress variation and prestress losses in HPC I-girder at the age of 0 days to 800 days. The predicted results of time-dependent behavior with the help of experimental and material models, and the model's error percentage difference worked out with the reference of HPC mix experimentally investigated.

\subsection{Deformations}

At the age of 800 days, the camber profile is predicted by analytical procedure using shrinkage and creep of the ACI, fib, B3, GL models and results are compared with computed camber using experimentally measured shrinkage and creep (see in Fig. 4). For each model the percentage error in predicting camber is worked out and observed for each are $+41 \%$ for ACI model, $-47 \%$ for $f i b$ model, $-135 \%$ for B3 model and $+98 \%$ for the GL model at the age of 800 days (see Table 2). The ACI and GL models

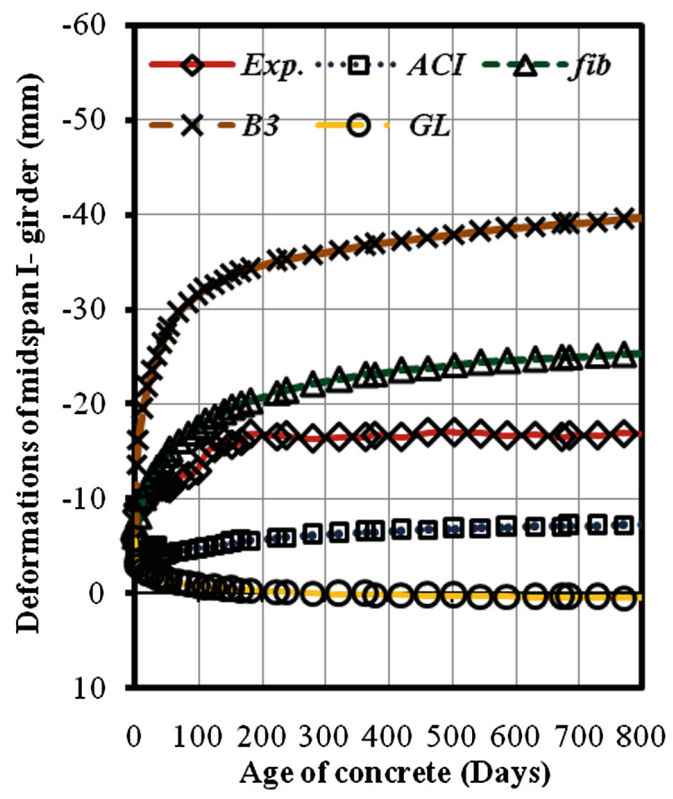

Fig. 4. Time-dependent deformations of simply supported I-girder 
Table 2. Time-dependent mid-span camber of I-girder at age of 800 days under LC

\begin{tabular}{|c|c|c|c|c|c|c|c|c|c|c|c|}
\hline \multirow[t]{3}{*}{$\begin{array}{l}\mathrm{HPC} \\
\operatorname{mix}\end{array}$} & \multirow{3}{*}{$\begin{array}{l}\text { Initial } \\
\text { prestressing }\left(f_{p i}\right) \\
\text { in } \mathrm{MPa}\end{array}$} & \multirow[t]{3}{*}{$\begin{array}{l}\text { Tendon area }\left(A_{p}\right) \\
\text { in } \mathrm{mm}^{2}\end{array}$} & \multirow[t]{3}{*}{$\begin{array}{l}\text { Camber }(\mathrm{mm}) \text { as per } \\
\text { exp. properties }\end{array}$} & \multicolumn{8}{|c|}{$\begin{array}{l}\text { Predicted camber }(\mathrm{mm}) \text { as per existing material } \\
\text { models and difference }(\%)\end{array}$} \\
\hline & & & & \multicolumn{2}{|l|}{ ACI } & \multicolumn{2}{|l|}{ fib } & \multicolumn{2}{|l|}{ B3 } & \multicolumn{2}{|l|}{ GL } \\
\hline & & & & Val. & Diff. & Val. & Diff. & Val. & Diff. & Val. & Diff. \\
\hline $\begin{array}{l}\text { M50 } \\
\text { grade }\end{array}$ & 1460 & 7 ply $\times 9^{*}=630$ & -17 & -10 & +41 & -25 & -47 & -40 & -135 & +0.4 & +98 \\
\hline
\end{tabular}

Note: Percentage difference in (-) range is over-predicted values and (+) range is under-predicted values.

usually underestimate the camber while the $f i b$ and B3 models overestimate. These outcomes indicated that the significance of realistic estimation of the shrinkage and creep prediction to predict time-dependent deformation behavior of I-girder made by the HPC. It has observed that the appropriate material model selection for long-term deformation prediction plays very important role in the analytical procedure. Also, there may be lots of deviation possible between predicted and actual deformations and as a results serviceability and sustainability problems will face during the service life of the structure. In this comparative study, the percentage prediction error difference by models is very high compared with experimental and therefore existing materials model need to improve their prediction performance of shrinkage and creep, especially for local condition and for HPC material properties.

\subsection{Stress Distribution}

In present work analysis performed to predict the stress distribution for top and bottom fiber of I-girder at the age of 0 days and 800 days using existing material models namely ACI, fib, B3 and GL. The results have been compared with the computed stresses for experimentally measured shrinkage and creep and shown in Tables 3 and 4 for LC. The percentage error in predicting bottom fiber stress at the age of 800 days is $-20.70 \%$ for ACI model, $+42.10 \%$ for $f i b$ model, $+121 \%$ for B 3 model and $-33.5 \%$ for GL model. In fact, this comparative study clearly shows that the accuracy of stress distribution in HPC girder fully depends on the influence of shrinkage and creep of HPC or the material model used to predict the stress distribution. Nevertheless, existing material models do not satisfactorily predict the long-term stress for indigenously made HPC properties and results in either overestimating or underestimating and may result in serviceability and sustainability problems in long-term behavior Geadam et al. (2013).

Table 3. Summary of stress distribution in I-girder for LC using experimental data

\begin{tabular}{l|l|l|l|l|l|l}
\hline HPC mix & \multicolumn{3}{|c|}{ Top fiber stress (MPa) } & \multicolumn{3}{l}{$\begin{array}{l}\text { Bottom fiber stress } \\
\text { (MPa) }\end{array}$} \\
\cline { 2 - 8 } & 0 day & 800 days & $\%$ diff. & 0 day & 800 days & $\%$ diff. \\
\hline M50 grade & 10.86 & 10.75 & 1.01 & 3.94 & 1.40 & 64.46 \\
\hline
\end{tabular}

Note: Top and bottom fiber stresses of I-girder reduced at age 0 days to 800 days. 
Table 4. Summary of bottom fiber stress distribution of I-girder for LC using material models at age 800 days

\begin{tabular}{|c|c|c|c|c|c|c|c|c|c|}
\hline \multirow[t]{2}{*}{$\begin{array}{l}\text { HPC } \\
\text { mix }\end{array}$} & \multirow[t]{2}{*}{$\begin{array}{l}\text { Stress }(\mathrm{MPa}) \text { as per } \\
\text { experimental properties }\end{array}$} & \multicolumn{8}{|c|}{$\begin{array}{l}\text { Predicted stress (MPa) as per existing material } \\
\text { models at the age of } 800 \text { days and the difference }(\%)\end{array}$} \\
\hline & & ACI & Diff. & fib & Diff. & B3 & Diff. & GL & Diff. \\
\hline $\begin{array}{l}\text { M50 } \\
\text { grade }\end{array}$ & 1.40 & 1.69 & -20.7 & 0.81 & +42.1 & -0.3 & +121 & 1.87 & -33.5 \\
\hline
\end{tabular}

Note: Percentage difference in $(-)$ range is over predicted results and $(+)$ range is under predicted results.

\subsection{Pre-stress Losses}

Pre-stress losses in HPC I-girder investigated using time-dependent steel relaxation equations proposed by Maguru et al. (1964) and results shown in Fig. 5. As seen in the comparative results of pre-stress loss, Table 5 at the age of 800 days that the overestimation of pre-stress loss can lead to excessive deformations (upward camber deflection) and uneconomic designs, while underestimation of pre-stress loss may result in excessive deformations (camber downward deflection) and even cracks in the tension region of I-girder. It can be observed from Table 5 that the average percentage error in predicting pre-stress loss in LC at the age of 800 days is $+7.60 \%$ for the ACI model, $-15.4 \%$ by the $f i b$ model, $-37.5 \%$ for the B 3 model and $+12.4 \%$ by the GL model respectively. In fact, this comparative study clearly shows that the long-term percentage error difference predicted by existing material models either an overestimation or underestimation.

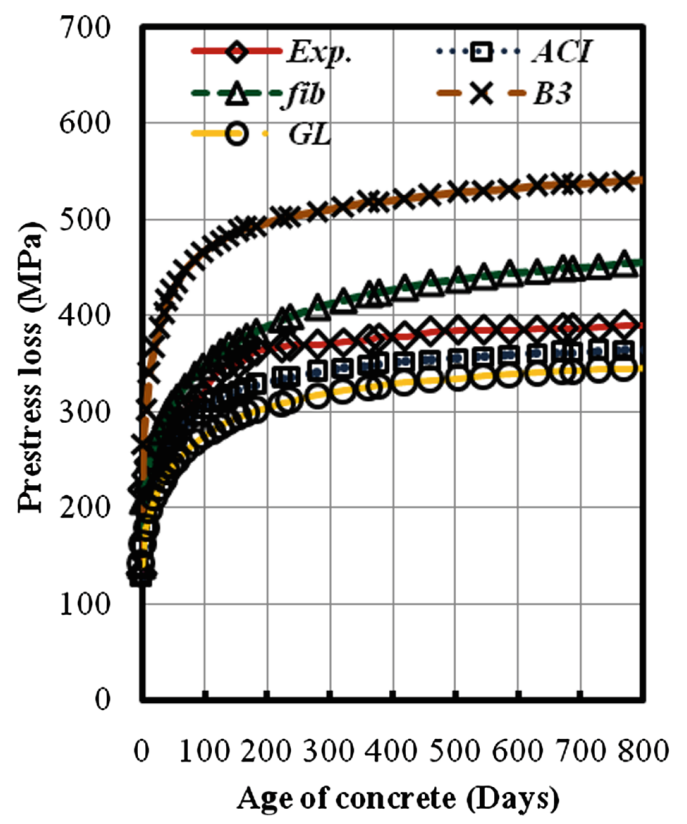

Fig. 5. Time-dependent pre-stress loss in simply supported I-girder 
Table 5. Summary of prestress loss in I-girder under LC-II at age 800 days

\begin{tabular}{|c|c|c|c|c|c|c|c|c|c|}
\hline \multirow[t]{2}{*}{$\begin{array}{l}\text { HPC } \\
\operatorname{mix}\end{array}$} & \multirow{2}{*}{$\begin{array}{l}\text { Prestress loss } \\
\text { (MPa) as per } \\
\text { experimental } \\
\text { properties }\end{array}$} & \multicolumn{8}{|c|}{$\begin{array}{l}\text { Predicted prestress loss }(\mathrm{MPa}) \text { as per existing material models at } \\
\text { the age of } 800 \text { days }\end{array}$} \\
\hline & & ACI & $\begin{array}{l}\% \\
\text { diff. }\end{array}$ & $f i b$ & $\begin{array}{l}\% \\
\text { diff. }\end{array}$ & B3 & $\begin{array}{l}\% \\
\text { diff. }\end{array}$ & GL & $\begin{array}{l}\% \\
\text { diff. }\end{array}$ \\
\hline Mix-II & 395 & 365 & +7.60 & 456 & -15.4 & 543 & -37.5 & 346 & +12.4 \\
\hline
\end{tabular}

Note: Percentage difference in $(-)$ range is over predicted results and $(+)$ range is under predicted results.

\section{Conclusions}

The importance of HPC shrinkage and creep properties and its prediction by using the existing material models for time-dependent behavior prediction of the HPC concrete bridge has been demonstrated. In fact, negligence and misunderstanding of such properties in design calculation may result in long-term sustainability, serviceability and even failure problems in bridge elements will face. Therefore, it is very important to improve the understanding of structural life-cycle performance by taking care effect of HPC properties. From this study some salient findings are:

- The percentage error in predicting camber is observed for each model are $+41 \%$ for the ACI model, $-47 \%$ for the $f i b$ model, $-135 \%$ for the B3 model and $+98 \%$ for the GL model at the age of 800 days. The ACI and GL models usually underestimate the camber while the $f i b$ and B3 models overestimate.

- The percentage error in predicting of bottom fiber stress of I-girder at the age of 800 days is $-20.70 \%$ for the ACI model, $+42.10 \%$ for the $f i b$ model, $+121 \%$ for the B3 model and $-33.5 \%$ for the GL model.

- The average percentage error in predicting of the pre-stress loss at the age of 800 days is $+7.60 \%$ for the ACI model, $-15.4 \%$ for the $f i b$ model, $-37.5 \%$ for the B3 model and $+12.4 \%$ for the GL model respectively.

An appropriate material model in the analysis process to meet the demand of optimistic design expectations with efficient and scientifically sound in very important. In fact, due to the scattered results and higher percentage error in prediction, it is very difficult to say which model is the best of the time-dependent properties prediction for HPC concrete bridges. Therefore, more study and improvement is needed in the prediction models, especially indigenous source concrete material properties.

\section{References}

American Concrete Institute Committee 209R-92. Prediction of creep, shrinkage, and temperature effects in concrete structures. ACI Special Publication, ACI (2008)

Bazant, Z.P., et al.: Pervasiveness of excessive segmental bridge deflections: wake-up call for creep. ACI Struct. J. 108(6), 766 (2011a). ACI

Bazant, Z.P., et al.: Excessive creep deflections: an awakening. Concr. Int. 33(8), 44-46 (2011b). ACI 
Bazant, Z.P., Baweja, S.: Creep and Shrinkage Prediction Model for Analysis and Design of Concrete Structures: Model B3. ACI Special Publication, ACI (2001)

CEB-FIP Model Code: Design of Concrete Structures. British Standard Institution, London (1990)

fib Model Code. International Federation for Structural Concrete. fib model code 2010, Lausanne, Switzerland (2010)

Gardner, N.J., Zhao, J.W.: Creep and shrinkage revisited. ACI Mater. J. (2001). ACI

Gedam, B.A., et al.: Influence of supplementary cementitious materials on shrinkage, creep, and durability of high-performance concrete. J. Mater. Civil Eng. (2015). ASCE, doi:10.1061/ (ASCE)MT.1943-5533.0001462

Gedam, B.A., et al.: An apt material model for drying shrinkage and specific creep of HPC using artificial neural network. Struct. Eng. Mech. (2014). Techno-Press, doi:10.11989/sem.2014. 52.1.097

Gedam, B.A., et al.: Performance of creep and shrinkage prediction models for normal strength concrete. Bridge Struct. Eng. (2013). IABSE

Maguru, et al.: A study of stress relaxation in prestressing reinforcement. Precast/Prestressed Concr. Instit. J. (1964). PCI

Mehta, P.K.: Durability - critical issues for the future. Concr. Int. (1997). ACI

Nilson, A.H.: Design of Prestressed Concrete, 2nd edn, New Delhi, India (1987)

PCI Committee on Prestress Losses. Recommendations for estimating prestress losses. Precast/Prestressed Concr. Inst. J. (1975). PCI 